\title{
Serum levels of gamma-glutamyl transpeptidase in relation to HCC human biology and prognosis
}

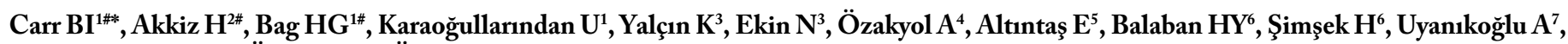
Balkan $A^{8}$, Kuran $S^{2}$, Üsküdar $\mathrm{O}^{2}$, Ülger $Y^{2}$, Güney $B^{2}$ and Delik $A^{2}$

${ }^{1}$ İnönü University, Malatya, Turkey

${ }^{2}$ Çukurova University, Adana, Turkey

${ }^{3}$ Dikle University, Diyarbakır, Turkey

${ }^{4}$ Eskişehir Osmangazi University, Eskişehir, Turkey

${ }^{5}$ Mersin University, Mersin, Turkey

${ }^{6}$ Hacettepe University, Ankara, Turkey

${ }^{7}$ Harran University, Şanlıurfa, Turkey

${ }^{8}$ Gaziantep University, Gazientep, Turkey

\#Authors contributed equally.

\begin{abstract}
Background and aim: Hepatocellular carcinoma (HCC) biomarkers are limited, as even the best studied, alpha-fetoprotein (AFP), is elevated in no more than $50 \%$ of HCC patients. The aim was to evaluate several serum liver function tests in relation to survival and tumor characteristics in a large cohort of Turkish HCC patients.

Methods: We retrospectively examined the serum levels of gamma glutamyl transpeptidase (GGT) in relation to patient survival.

Results: Kaplan-Meier analysis showed that only GGT and albumin amongst liver function tests, were significantly associated with survival. Survival worsened with increase in GGT levels semi-quantitatively. Increase in GGT levels was also found to significantly correlate with an increase in maximum tumor diameter from 4.5 to $7 \mathrm{~cm}$, a 20-fold increase in serum alpha-fetoprotein level, an increase in tumor multifocality from 20 to $54 \%$ of patients, and a doubling in percent of patients with portal vein thrombosis (PVT) from 20 to 40\%. Serum GGT levels also showed significant survival differences for patients with low AFP levels. A doublet combination of serum GGT with albumin levels was associated with higher hazard ratios in a Cox regression analysis, as compared with single parameter GGT. The combination parameter pair was also prognostically useful in the low-AFP patient subcohort and was associated with significant differences in patient tumor characteristics.

Conclusions: Serum GGT levels and especially combination serum GGT plus albumin levels, were significantly associated both with HCC patient survival and tumor aggressiveness characteristics, regardless of AFP levels in a large Turkish cohort. This might be especially useful since the majority of HCC patients do not have elevated levels of AFP.
\end{abstract}

\begin{abstract}
Abbreviations: HCC: Hepatocellular carcinoma; PVT: Portal vein thrombosis; AFP: Alpha-fetoprotein; GGTP: Gamma glutamyl transpeptidase; ALKP: Alkaline phosphatase; AST: Aspartate aminotransferase; ALT: Alanine aminotransferase; Alb: Albumin; CRP: C-reactive protein; ESR: Erythrocyte sedimentation rate; $\mathrm{Hb}$ : Hemoglobin; Plt: Platelets; T. bili: Total bilirubin; HDL: High density lipoprotein cholesterol; LDL: Low density lipoprotein cholesterol; MTD: Maximum tumor diameter; CT: Computerized axial tomography; MRI: Magnetic resonance imaging.
\end{abstract}

\section{Introduction}

Hepatocellular carcinoma (HCC) prognosis has in general been shown to depend on 2 separate yet related considerations, namely tumor and non-tumor characteristics. The former includes tumor size and multiplicity, presence or absence of portal vein invasion by tumor (PVT), degree of tumor differentiation, serum levels of serum alphafetoprotein [1-4] and an immature form of prothrombin called desgamma carboxy prothrombin or DCP [5], which in turn is associated with increased incidence of PVT [6]. The latter includes inflammation and other damage to the underlying liver, as reflected in standard clinical liver function tests $[7,8]$ and more recently in parameters of systemic inflammation, including platelet-lymphocyte ratio, neutrophil-lymphocyte ratio, C-reactive protein $[9,10]$ and albumin [11] as well as many novel biomarkers and their combinations that are currently under study [12-14].

Amongst the standard liver function tests, gamma-glutamyl transpeptidase (GGT) stands out as being associated experimentally

${ }^{\star}$ Correspondence to: Brian I. Carr MD, FRCP, PhD, Liver Transplant Institute, Inonu University, Bulgurlu Mah, Elazig Yolu 15 km, 44289 Merkez Battalgazi, Malatya, Turkey, E-mail: brianicarr@hotmail.com

Key words: HCC, survival, GGT

Received: September 05, 2020; Accepted: September 15, 2020; Published: September 17, 2020 
with pre-neoplastic HCC lesions [15,16]. GGT, also known as gammaglutamyl transferase, has been thought to play a role in HCC growth and development and in resistance to drug toxicity [16,17], being a cell surface enzyme that is involved in glutathione metabolism and is thus important in the maintenance of cellular cysteine levels. Furthermore, GGT has also been considered to be a clinically important prognostic factor [18-21].

In the current work, the significance of serum levels of GGT alone or in combination with other liver function parameters, especially albumin, has been examined in relation to HCC survival and to clinical tumor characteristics. GGT was found to be a useful biomarker for prognosis and for tumor aggressiveness parameters, including in patients with small tumors or in HCC patients who have low serum AFP levels.

\section{Methods}

Patient data: We retrospectively analyzed a database of 470 prospectively-accrued non-transplant HCC patients who had both survival data and baseline tumor parameter data, including CT scan information on HCC maximum tumor diameter (MTD), number of tumor nodules and presence or absence of macroscopic portal vein thrombosis (PVT), as well as serum alpha-fetoprotein (AFP) levels; complete blood count; routine serum liver function tests, (total bilirubin, GGTP, ALKP, albumin, transaminases, and patient demographics. Diagnosis was made either via tumor biopsy or according to international guidelines. Database management conformed to legislation on privacy and this study conforms to the ethical guidelines of the Declaration of Helsinki and approval for this retrospective study on de-identified HCC patients was obtained by the Institutional Review Board of each participating institution, as previously reported [22].

\section{Statistical analysis}

Continuous variables were summarized by median, minimum and maximum values. Comparisons between two groups were performed by Mann Whitney $U$ test. For more than two groups, Kruskal-Wallis test and Conover post-hoc method was used. Categorical variables were expressed as count and percentage, comparisons according to these variables were made by Pearson's chi-square, continuity corrected chisquare or Fisher's exact test where appropriate. Kaplan-Meier method and Log-Rank test were used for survival analysis. Cox regression was used for Hazard Ratio (HR) estimations. In all analysis two-tailed significance level was considered as 0.05 . IBM SPSS Statistics for Windows version 22.0 (NY, USA) was used for statistical analysis.

\section{Results}

\section{Kaplan-Meier survival analysis for the total cohort}

A Kaplan-Meier Survival Analysis for the total HCC cohort was performed, using the clinical tumor characteristics and laboratory liver function characteristics (Table 1). Significance was found for all 4 clinical tumor characteristics of maximum tumor diameter (MTD), tumor number, macroscopic portal vein thrombosis (PVT) and serum alpha-fetoprotein (AFP) levels, as expected. For the remaining blood parameters, total bilirubin levels, alkaline phosphatase (ALKP) levels and platelet counts were not found to be significant, but serum levels of liver function parameters gamma glutamyl transpeptidase (GGT), albumin and aspartate aminotransferase (AST) were found to be significant for survival.

Table 1. Kaplan-Meier Survival Analysis for total HCC cohort $(n=470)$

\begin{tabular}{|c|c|c|c|c|}
\hline & & \multicolumn{2}{|c|}{ Survival time } & \multirow[b]{2}{*}{$\mathbf{p}$} \\
\hline & & Mean \pm SE & $\operatorname{Median} \pm$ SE & \\
\hline Overall & & $66.25 \pm 4.29$ & $31 \pm 3.03$ & \\
\hline \multirow{3}{*}{$\operatorname{MTD}(\mathrm{cm})$} & $<3$ & $53.00 \pm 6.47^{\mathrm{a}}$ & $36 \pm 8.22$ & \\
\hline & $3-5$ & $54.69 \pm 5.50^{\mathrm{a}}$ & $30 \pm 6.89$ & 0.023 \\
\hline & $>5$ & $40.87 \pm 3.54^{b}$ & $24 \pm 3.10$ & \\
\hline \multirow{2}{*}{ PVT } & No & $52.92 \pm 3.40$ & $31 \pm 3.13$ & \multirow{2}{*}{$<0.001$} \\
\hline & Yes & $26.24 \pm 3.88$ & $9 \pm 1.48$ & \\
\hline \multirow{3}{*}{$\mathrm{AFP}, \mathrm{IU} / \mathrm{mL}$} & $<100$ & $76.89 \pm 5.91^{\mathrm{a}}$ & $46 \pm 7.59$ & \multirow{3}{*}{$<0.001$} \\
\hline & $100-1000$ & $41.20 \pm 5.11^{\mathrm{b}}$ & $23 \pm 3.60$ & \\
\hline & $>1000$ & $39.20 \pm 5.29^{\mathrm{b}}$ & $24 \pm 5.55$ & \\
\hline \multirow{2}{*}{ Multifocality } & 1 & $55.00 \pm 3.66$ & $31 \pm 5.46$ & \multirow{2}{*}{0.004} \\
\hline & $>1$ & $39.85 \pm 4.10$ & $24 \pm 4.24$ & \\
\hline \multirow{2}{*}{ Platelets, $10^{3} / \mu \mathrm{L}$} & $\leq 125$ & $53.82 \pm 4.27$ & $31 \pm 4.14$ & \multirow{2}{*}{0.288} \\
\hline & $>125$ & $63.25 \pm 6.13$ & $29 \pm 3.59$ & \\
\hline \multirow{2}{*}{ Albumin,g/dL } & $\leq 3,5$ & $48.85 \pm 3.37$ & $26 \pm 2.99$ & \multirow{2}{*}{$<0.001$} \\
\hline & $>3,5$ & $83.57 \pm 8.01$ & $48 \pm 6.16$ & \\
\hline \multirow{2}{*}{ T.BIL (mg/dL) } & $\leq 1,5$ & $82.18 \pm 6.81$ & $48 \pm 7.13$ & \multirow{2}{*}{0.109} \\
\hline & $>1,5$ & $55.46 \pm 5.50$ & $29 \pm 5.07$ & \\
\hline \multirow{2}{*}{ ALKP, IU/mL } & $\leq 100$ & $61.36 \pm 5.17$ & $45 \pm 8.53$ & \multirow{2}{*}{0.511} \\
\hline & $>100$ & $80.81 \pm 7.49$ & $48 \pm 8.13$ & \\
\hline \multirow{2}{*}{ GGT, IU/mL } & $\leq 100$ & $88.52 \pm 6.64$ & $48 \pm 7.13$ & \multirow{2}{*}{0.002} \\
\hline & $>100$ & $41.72 \pm 4.20$ & $26 \pm 3.45$ & \\
\hline \multirow{2}{*}{ AST, IU/mL } & $\leq 40$ & $102.44 \pm 10.36$ & $84 \pm 17.93$ & \multirow{2}{*}{$<0.001$} \\
\hline & $>40$ & $53.15 \pm 3.97$ & $28 \pm 3.28$ & \\
\hline
\end{tabular}

Abbreviations: GGT: Gamma glutamyl transpeptidase (IU/mL); ALB: Albumin (g/dL); AST: Aspartate aminotransferase (IU/L); ALKP: Alkaline phosphatase (IU/mL); T. BIL: Total bilirubin (mg/dL); AFP: Alpha-fetoprotein (IU/mL); MTD: Maximum tumor diameter; PVT: Macroscopic portal vein thrombosis 


\section{Serum GGT levels in relation to survival and tumor characteristics}

Serum GGT levels for the total cohort were trichotomized, and the 3 resulting terciles were examined for their relationship to survival (Tables 2) (Figure 1). Mean survival was found to be 111.18 months (mo.) for GGT levels $<30 \mathrm{IU} / \mathrm{mL}, 61.72 \mathrm{mo}$. for GGT levels of 30$100 \mathrm{IU} / \mathrm{mL}$ and $41.72 \mathrm{mo}$. for GGT levels $>100 \mathrm{IU} / \mathrm{ml}, \mathrm{p}=0.001$. The tumor characteristics associated with these 3 GGT terciles were then examined. Statistically significant increases in MTD, AFP levels, tumor number and percent of patients with macroscopic PVT were found with each increase in GGT level (Table 3). GGT levels were then examined in relation to the smallest diameter tumors in the cohort (Table 4). GGT levels increased with each MTD cohort and significant increases were found for tumors $<5 \mathrm{~cm}$ compared to $5-10 \mathrm{~cm}$; however, levels for $<2$ $\mathrm{cm}$ versus $>2-5 \mathrm{~cm}$ were not significantly different, both for absolute serum GGT values and for percent of patients with serum GGT $>100$ $\mathrm{IU} / \mathrm{mL}$.

The serum GGT terciles were then examined in patients with low serum AFP $<100 \mathrm{IU} / \mathrm{mL}$ levels. The results also showed significantly longer (3-fold) survival for patients with low GGT levels $<30 \mathrm{IU} / \mathrm{mL}$ as compared with highest GGT levels $>100 \mathrm{IU} / \mathrm{mL}$ (Table 5).

In the $\mathrm{AFP}<100 \mathrm{IU} / \mathrm{mL}$ group, GGTP terciles showed differences in the tumor characteristics, with significantly more tumor multifocality and percent of patients with PVT in the high CRP group compared to the low CRP group (Table 6).

\section{Parameter doublet combinations with GGT}

Combinations of serum GGT alone or with either serum albumin or ALKP were then examined separately for smaller $<5 \mathrm{~cm}$ and larger $>5 \mathrm{~cm}$ tumors. For the combinations of GGT with albumin, significant differences in survival were found for high or low levels, regardless of whether patients with smaller $(<5 \mathrm{~cm}$ MTD) or larger ( $>5 \mathrm{~cm}$ MTD) tumors were examined (Table 7). The HRs for the combinations of GGT with albumin were greater than for GGT alone. Addition of ALKP to GGT however, resulted in significant survival differences only for patients with larger tumors.

\section{Serum levels of GGT plus albumin together}

The clinical correlates of the combination of serum GGT plus albumin levels together, were then examined (Table 8). Normal/low combination levels (GGT $<100 \mathrm{IU} / \mathrm{mL}$ plus albumin $>3.5 \mathrm{~g} / \mathrm{dL}$ ) were compared to abnormal/high combination levels (GGT $>100 \mathrm{IU} / \mathrm{mL}$ and albumin $<3.5 \mathrm{~g} / \mathrm{dL}$ ). Table 8 shows that almost every blood clinical parameter was different, when normal versus abnormal combination parameters were compared, except for platelets and LDL. Especially notable was the greater that 6 -fold difference in CRP levels between the 2 groups. Similarly, when the tumor characteristics between the 2 groups were compared, every tumor parameter (MTD, AFP, tumor number, percent patients with PVT) were significantly worse in the abnormal/high combination parameter GGT plus albumin pair, compared to the low/normal GGT plus albumin combination values, all $\mathrm{p}<0.001$ (Table 9 ). These tumor parameter differences were also found to all be significant for patients with large $>5 \mathrm{~cm}$ tumors (Table 9); but for patients with small $<5 \mathrm{~cm}$ tumors, none of the tumor parameters were significantly different (Table 9 ).

\section{Discussion}

The results reported here are of newly available survival data from a recently formed Turkish multi-institutional HCC collaborative group [22]. Kaplan-Meier analysis showed 4 out of 6 significant liver factors for survival, including GGT, AST, albumin and AST, but not bilirubin or ALKP. AFP was significant but was not included in further analysis or model-building, as less than $60 \%$ of HCC patients have elevated levels

Table 2. Serum GGT levels in relation to survival (For total cohort; all differences are statistically significant. Abbreviation: GGT, gamma glutamyl transpeptidase, (IU/mL)

\begin{tabular}{|c|c|c|c|c|c|c|}
\hline & & \multicolumn{2}{|c|}{ Survival time (mo) } & \multirow{2}{*}{$\begin{array}{c}\text { Log-rank } \\
\text { p-value }\end{array}$} & \multirow{2}{*}{$\begin{array}{c}\text { Univariate Cox } \\
\text { Regression } \\
\text { HR (95\%C.I.) }\end{array}$} & \multirow{2}{*}{$\begin{array}{c}\text { HR } \\
\text { p-value }\end{array}$} \\
\hline & & $\operatorname{Mean} \pm \mathrm{SE}$ & $\operatorname{Median} \pm \mathrm{SE}$ & & & \\
\hline \multirow{3}{*}{ Total cohort } & GGT $<30 \mathrm{IU} / \mathrm{mL}$ & $111.18 \pm 13.04^{\mathrm{a}}$ & NA & \multirow{3}{*}{0.001} & reference & \\
\hline & $\mathrm{GGT} \geq 30-100 \mathrm{IU} / \mathrm{mL}$ & $61.72 \pm 4.71^{\mathrm{b}}$ & $48 \pm 8.80$ & & $1.59(0.99-2.52)$ & 0.052 \\
\hline & GGT>100 IU/mL & $41.72 \pm 4.20^{\mathrm{c}}$ & $26 \pm 3.45$ & & $2.22(1.38-3.56)$ & 0.001 \\
\hline
\end{tabular}

Table 3. Tumor characteristics as a function of serum GGT levels

\begin{tabular}{|c|c|c|c|c|}
\hline & GGT<30 IU/mL & GGT $\geq 30-100 \mathrm{IU} / \mathrm{mL}$ & GGT>100 IU/mL & \\
\hline & Median (min.-max.) & Median (min.-max.) & Median (min.-max.) & $\mathrm{p}$ \\
\hline MTD size & $4.5(1-16)$ & $5(1-24)$ & $7(0.8-20.5)$ & $<0.001$ \\
\hline \multirow[t]{2}{*}{ AFP } & $9.3(1.2-12768)$ & $37.1(0.5-918965)$ & $207.8(0.5-600000)$ & $<0.001$ \\
\hline & $\%$ & $\%$ & $\%$ & $\mathrm{p}$ \\
\hline Tumor $\# \leq 2$ & 80.0 & 62.7 & 45.6 & \multirow{2}{*}{$<0.001$} \\
\hline Tumor \# $>2$ & 20.0 & 37.3 & 54.4 & \\
\hline PVT (-) & 78.8 & 75.9 & 59.6 & \multirow{2}{*}{$<0.001$} \\
\hline $\operatorname{PVT}(+)$ & 21.2 & 24.1 & 40.4 & \\
\hline
\end{tabular}

Abbreviations: GGT: Gamma glutamyl transpeptidase: (IU/mL); MTD: Maximum tumor diameter; AFP: Alpha-fetoprotein; PVT: Macroscopic portal vein thrombosis

Table 4. Smallest tumor size with elevated serum GGT. Superscript ${ }^{\mathrm{a}}$ groups are not different from each other, but are significantlydifferent to superscript ${ }^{\mathrm{b}}$ groups

\begin{tabular}{|c|c|c|}
\hline MTD size & $\begin{array}{c}\text { Serum GGT values, IU/mL } \\
\text { Mean (median;min-max) }\end{array}$ & $\begin{array}{c}\text { \% GGT }>\mathbf{1 0 0} \\
\text { IU/mL }\end{array}$ \\
\hline$\leq 2 \mathrm{~cm}$ & $111.25(58.5 ; 13-520)^{\mathrm{a}}$ & $36.4^{\mathrm{a}}$ \\
\hline$>2-5 \mathrm{~cm}$ & $121.71(80 ; 11-1184)^{\mathrm{a}}$ & $38.7^{\mathrm{a}}$ \\
\hline$>5-10 \mathrm{~cm}$ & $174.11(103 ; 12-1058)^{\mathrm{b}}$ & $52.4^{\mathrm{b}}$ \\
\hline p-value & $<0.001$ & 0.021 \\
\hline
\end{tabular}


Carr BI (2020) Serum levels of gamma-glutamyl transpeptidase in relation to HCC human biology and prognosis

Table 5. Kaplan-Meier Survival Analysis for low AFP $(<100 \mathrm{IU} / \mathrm{mL})$ patients Superscript ${ }^{\mathrm{a}}$ groups are not different from each other but are significantly different to superscript ${ }^{\mathrm{b}}$ groups

\begin{tabular}{|c|c|c|c|c|}
\hline & & & \multicolumn{2}{|c|}{ Survival time } \\
\hline & & Mean \pm SE & Median \pm SE \\
\hline Overall & & $76.89 \pm 65.31$ & $46 \pm 7.59$ \\
\hline \multirow{2}{*}{ MTD $(\mathrm{cm})$} & $<5$ & $60.59 \pm 5.73$ & $38 \pm 12.58$ \\
\cline { 2 - 4 } & $<5$ & $46.40 \pm 4.41$ & $35 \pm 5.61$ \\
\hline & $30-100$ & $123.15 \pm 15.48^{\mathrm{a}}$ & NA \\
\hline & $>100$ & $61.44 \pm 5.21^{\mathrm{b}}$ & $57 \pm 10.82$ \\
\hline
\end{tabular}

Abbreviations: GGT: Gamma glutamyl transpeptidase: (IU/mL); MTD: Maximum tumor diameter

Table 6. Tumor characteristics as a function of serum GGT levels, within low AFP $(<100 \mathrm{IU} / \mathrm{mL})$

\begin{tabular}{|c|c|c|c|c|}
\hline & GGT $<\mathbf{3 0} \mathbf{I U} / \mathbf{m L}$ & GGT $\geq 30-100 \mathrm{IU} / \mathrm{mL}$ & GGT>100 IU/mL & \\
\hline & Median (min.-max.) & Median (min.-max.) & Median (min.-max.) & $\mathbf{p}$ \\
\hline MTD size & $5(1-16)$ & $5(1-24)$ & $6(0.8-20.5)$ & 0.051 \\
\hline \multirow[t]{2}{*}{ AFP } & $4.5(1.2-98.1)^{\mathrm{a}}$ & $10(0.5-99)^{b}$ & $9.1(0.5-95.9)^{b}$ & 0.010 \\
\hline & $\%$ & $\%$ & $\%$ & $\mathrm{p}$ \\
\hline Tumor $\# \leq 2$ & 78.4 & 68.1 & 51.5 & \multirow{2}{*}{0.005} \\
\hline Tumor \# $>2$ & 21.6 & 31.9 & 48.5 & \\
\hline PVT (-) & 83.3 & 83.8 & 67.0 & \multirow{2}{*}{0.009} \\
\hline PVT (+) & 16.7 & 16.2 & 33.0 & \\
\hline
\end{tabular}

Superscript ${ }^{\mathrm{a}}$ groups are not different from each other, but are significantly different to superscript ${ }^{\mathrm{b}}$ groups. Abbreviations: GGT: Gamma glutamyl transpeptidase: (IU/mL); MTD: Maximum tumor diameter; AFP: Alpha-fetoprotein; PVT: Macroscopic portal vein thrombosis

Table 7. Univariate Kaplan-Meier and Cox regression analysis for duplicate parameters

\begin{tabular}{|c|c|c|c|c|c|c|}
\hline & & \multicolumn{2}{|c|}{ Survival time } & \multirow{2}{*}{$\begin{array}{c}\text { Log-rank } \\
\text { p-value }\end{array}$} & \multirow{2}{*}{$\begin{array}{c}\text { Univariate Cox } \\
\text { Regression } \\
\text { HR (95\%C.I.) }\end{array}$} & \multirow{2}{*}{$\begin{array}{c}\text { HR } \\
\text { p-value }\end{array}$} \\
\hline & & $\operatorname{Mean} \pm \mathrm{SE}$ & Median \pm SE & & & \\
\hline \multirow{2}{*}{$\mathrm{MTD}<5 \mathrm{~cm}$} & GGT $\leq 100$ & $69.67 \pm 5.74$ & $60 \pm 19.01$ & \multirow{2}{*}{0.023} & reference & \\
\hline & GGT $>100$ & $40.23 \pm 5.82$ & $38 \pm 12.15$ & & $1.73(1.07-2.81)$ & 0.026 \\
\hline \multirow{2}{*}{$\mathrm{MTD} \geq 5 \mathrm{~cm}$} & GGT $\leq 100$ & $54.29 \pm 5.85$ & $36 \pm 8.03$ & \multirow{2}{*}{0.011} & reference & \\
\hline & GGT $>100$ & $26.01 \pm 3.34$ & $24 \pm 4.93$ & & $1.63(1.11-2.39)$ & 0.013 \\
\hline \multirow{2}{*}{$\mathrm{MTD}<5 \mathrm{~cm}$} & GGT $\leq 100 \&$ ALB $>3.5$ & $83.03 \pm 8.42$ & NA & \multirow{2}{*}{0.002} & reference & \\
\hline & GGT $>100 \&$ ALB $\leq 3.5$ & $40.74 \pm 7.58$ & $38 \pm 10.24$ & & $2.99(1.45-6.19)$ & 0.003 \\
\hline \multirow{2}{*}{$\mathrm{MTD} \geq 5 \mathrm{~cm}$} & $\mathrm{GGT} \leq 100 \&$ ALB $>3.5$ & $63.10 \pm 7.95$ & $45 \pm 8.50$ & \multirow{2}{*}{$<0.001$} & reference & \\
\hline & GGT $>100 \&$ ALB $\leq 3.5$ & $28.12 \pm 3.93$ & $24 \pm 5.82$ & & $2.67(1.52-4.71)$ & 0.001 \\
\hline \multirow{2}{*}{$\mathrm{MTD}<5 \mathrm{~cm}$} & $\mathrm{GGT} \leq 100 \& \mathrm{AST} \leq 40$ & $86.29 \pm 8.53$ & NA & \multirow{2}{*}{0.001} & reference & \\
\hline & GGT $>100 \&$ AST $>40$ & $37.68 \pm 5.95$ & $38 \pm 9.21$ & & $3.01(1.47-6.14)$ & 0.002 \\
\hline \multirow{2}{*}{$\mathrm{MTD} \geq 5 \mathrm{~cm}$} & $\mathrm{GGT} \leq 100 \&$ AST $\leq 40$ & $53.94 \pm 8.33$ & $52 \pm 12.19$ & \multirow{2}{*}{0.005} & reference & \\
\hline & GGT $>100 \&$ AST $>40$ & $21.10 \pm 3.31$ & $16 \pm 3.45$ & & $2.25(1.25-4.07)$ & 0.007 \\
\hline \multirow{2}{*}{$\mathrm{MTD}<5 \mathrm{~cm}$} & $\begin{array}{c}\text { GGT } \leq 100 \& \& \\
\text { ALKP }>100\end{array}$ & $73.80 \pm 9.86$ & NA & \multirow{2}{*}{0.346} & reference & \\
\hline & $\begin{array}{c}\text { GGT }>100 \& \\
\text { ALKP } \leq 100\end{array}$ & $36.66 \pm 7.93$ & $26 \pm 11.72$ & & $1.57(0.61-4.05)$ & 0.352 \\
\hline \multirow{2}{*}{$\mathrm{MTD} \geq 5 \mathrm{~cm}$} & $\begin{array}{c}\text { GGT } \leq 100 \& \\
\text { ALKP }>100\end{array}$ & $56.33 \pm 8.21$ & $30 \pm 16.02$ & \multirow{2}{*}{0.037} & reference & \\
\hline & $\begin{array}{c}\text { GGT }>100 \& \\
\text { ALKP } \leq 100\end{array}$ & $13.11 \pm 5.29$ & $9 \pm 5.00$ & & $2.66(1.01-7.02)$ & 0.048 \\
\hline
\end{tabular}

Abbreviations: MTD: Maximum tumor diameter; GGT: Gamma Glutamyl transpeptidase (IU/mL); ALB: Albumin (g/dL); AST: Aspartate aminotransferase (IU/L); ALKP: Alkaline phosphatase (IU/Ml) 
Table 8. Lab values in patients with high or low serum GGTP and Albumin levels in total cohort

\begin{tabular}{|c|c|c|c|}
\hline & GGTP $\leq 100 \&$ ALB $>3.5 \&$ AST $\leq 40$ & GGTP $>100 \&$ ALB $\leq 3.5 \&$ AST $>40$ & \\
\hline & Median (min.-max.) & Median (min.-max.) & $\mathbf{p}$ \\
\hline $\mathrm{Hb}, \mathrm{g} / \mathrm{dL}$ & $14.2(9.3-17.6)$ & $11.9(5.7-17.1)$ & $<0.001$ \\
\hline Plat, $10^{3} / \mu \mathrm{L}$ & $163.5(35-387)$ & $166.5(13-2700000)$ & 0.757 \\
\hline Albumin, $\mathrm{g} / \mathrm{dL}$ & $3.8(3.53-4.88)$ & $2.6(1.2-3.5)$ & $<0.001$ \\
\hline $\mathrm{CRP}, \mathrm{md} / \mathrm{dL}$ & $1(0.168-162.57)$ & $6(0.13-230.07)$ & $<0.001$ \\
\hline ALKP, IU/mL & $79(36-335)$ & $202.5(46-1103)$ & $<0.001$ \\
\hline GGT, IU/mL & $32(12-90)$ & $211(101-1286)$ & $<0.001$ \\
\hline AST, IU/mL & $29(13-39)$ & $108(41-2061)$ & $<0.001$ \\
\hline T.BİL, mg/dL & $0.835(0.22-2.1)$ & $1.9(0.3-33.99)$ & $<0.001$ \\
\hline Cholesterol, mg/dl & $1.14(0.9-2.29)$ & $1.27(0.85-6.06)$ & $<0.001$ \\
\hline ALT, IU/mL & $23(7-64)$ & $62(11-942)$ & $<0.001$ \\
\hline $\mathrm{HDL}, \mathrm{mg} / \mathrm{dL}$ & $43(16-96)$ & $27.55(5-89)$ & $<0.001$ \\
\hline $\mathrm{LDL}, \mathrm{mg} / \mathrm{dL}$ & $105(40.6-237)$ & $97.5(26-310)$ & 0.305 \\
\hline
\end{tabular}

GGT: Gamma glutamyl transpeptidase: (IU/mL); ALB: Albümin (g/dL); AST: Aspartate aminotransferase (IU/L); Plat: Platelets. Other parameter abbreviations on front page.

Table 9. Tumor characteristics in patients with high or low serum GGTP and Albumin levels

\begin{tabular}{|c|c|c|c|}
\hline & GGTP $\leq 100 \&$ ALB $>3.5 \&$ AST $\leq 40$ & GGTP $>100 \&$ ALB $\leq 3.5 \&$ AST $>40$ & \\
\hline & Median (min.-max.) & Median (min.-max.) & $\mathbf{p}$ \\
\hline MTD size & $4.8(1.3-16)$ & $7(0.8-20.5)$ & 0.003 \\
\hline \multirow[t]{2}{*}{ AFP } & $11.2(1.8-51287)$ & $236.5(1-600000)$ & $<0.001$ \\
\hline & $\%$ & $\%$ & \\
\hline Tumor \# $\leq 2$ & 69.8 & 43.6 & \multirow{2}{*}{0.004} \\
\hline Tumor \# >2 & 30.2 & 56.4 & \\
\hline PVT (-) & 86.0 & 58.9 & \multirow{2}{*}{$<0.001$} \\
\hline PVT $(+)$ & 14.0 & 41.1 & \\
\hline
\end{tabular}

Abbreviations: MTD: Maximum tumor diameter (cm); AFP: Alpha-fetoprotein (IU/mL); PVT: Macroscopic portal vein thrombosis; GGT: Gamma glutamyl transpeptidase: (IU/mL); ALB: Albümin (g/dL); AST: Aspartate aminotransferase (IU/L)

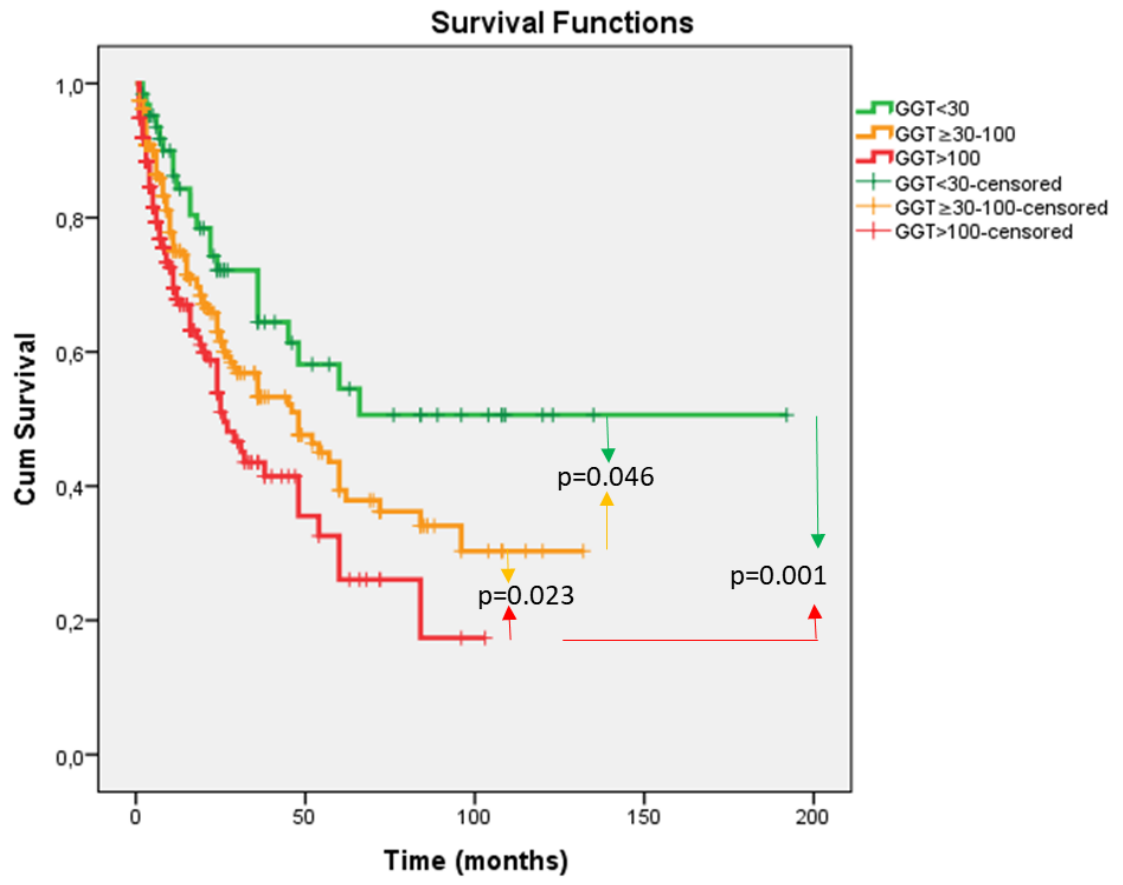

Figure 1. Cumulative survival (mo) as a function of serum GGT levels 
[23-25]. Focus was initially made on GGT, due to previous reports on its importance as a biomarker in experimental hepatocarcinogenesis, as well as several reports of its potential as a clinical HCC prognostic biomarker [15-21]. We found that increasing serum GGT levels were not only significantly associated with decreasing survival, but also with significantly worse levels of the 4 tumor parameters-MTD, tumor multifocality, serum AFP levels and percent of patients with macroscopic PVT. For the mean survival times, each serum GGT level was significantly different from each other serum GGT level. Patients with different MTD size bands were further examined for GGT levels and percent with elevated GGT, to determine if GGT might be useful for the search for very small tumors. Although there was an increase in serum GGT levels for each size band, we could not discriminate between patients in the $<5 \mathrm{~cm}$ MTD bands. The same approach was taken to examine the important low AFP group of patients in relation to serum GGT levels. The 2 GGT groups showed a 3-fold survival difference in the total cohort and in the groups with different serum GGT levels. The 4 tumor characteristics were all worse for the shorter survival, highest serum GGT level group as compared with the longer survival, lowest serum GGT level group, especially with multifocality and percent of patients with PVT being significantly different in the 2 GGT groups.

Serum GGT levels were also combined with serum albumin levels to form parameter doublets. The hazard ratios (HRs) of the doublets were higher than for singlet GGT alone, when patients with either smaller or larger size tumors were considered separately. However, addition of ALKP to GGT did not improve on GGT-related survival for smaller tumors. Combination serum liver parameters were then examined, using doublet GGT plus albumin, and survivals for patients with normal/low doublet combination parameters were found to be significantly higher (2-fold) than for patients with abnormal doublet combination values, whether patients with larger or with smaller tumors were considered and this combination of parameters was better (higher HR) for predicting survival than GGT levels alone. When the 2 combination groups were compared for tumor characteristics, the patients in the worse survival group had significantly worse values for all 4 tumor parameters than for the better survival group.

GGT has been thought to be an HCC biomarker for many years $[15,16,18-21]$, even though it has not been in general clinical practice or decision-making paradigms. However, there is a recent increase in its consideration as a practical marker [19-21], especially for that group of almost $50 \%$ of HCC patients who do not have elevated AFP [22-25]. Furthermore, there have been several other reports of the usefulness of GGT in combination with other markers [26-31], as well as a metaanalysis [32]. Of particular note in our analysis, was the usefulness of combination GGT plus albumin in the low-AFP cohort, for whom there are few other validated tumor markers (Tables 11 and 12). There was a significant, 3-fold difference in survival between these 2 groups of lowAFP patients, as well as significant differences in tumor characteristics. Thus, the prognostic usefulness of combination GGT plus albumin are confirmed in this study, in addition to the findings in Chinese HCC patients $[26,27]$.

What might be the functions of HCC in either tumorigenesis or in conjunction with other factors involved in its usefulness in prognosis? GGT has been considered as a biomarker for liver damage and alcohol abuse [33] and is likely associated with hepatic inflammation $[30,34]$. It is a membrane-bound enzyme involved in the metabolism of glutathione by transferring $\gamma$-glutamyl groups and glutathione is a cellular thiol-antioxidant, which can protect cells from oxidant damage by neutralizing reactive oxygen species and free radicals $[16,17]$. Thus, cellular GGT levels increase under oxidative stress. Conversely, GGT has also been reported to be both a mediator of oxidative cell damage via an increase of reactive oxygen species [35,36], which in turn induce inflammation and contribute to hepatocarcinogenesis, as well as being involved in resistance to cell cytotoxicity by increasing cellular cysteinyl-glycine levels $[16,17,37,38]$. Precisely how GGT might contribute to HCC growth and invasiveness (PVT) has not been clearly explained. One possible mechanism is through its mediation of free-radical associated mutagenesis [35]. Other possible means are the involvement of the GGT pathway in cell-cycle arrest mechanisms [39] or through metabolomics re-wiring [40]. In addition, GGT deficiency has been shown to be associated experimentally with growth retardation, offering a possible set of mechanisms for an association of over-expression and growth promotion [41,42]. It is also an oncofetal protein $[43,44]$, similar in this respect to AFP. Finally, an HCCspecific GGT isozyme has been the subject of multiple reports [45-48]. Its function could be consistent with tumor cell growth or metabolism or drug resistance; in fact, they might all be linked.

\section{Conclusion}

This report therefore extends previous observations in a large nonsurgical series, by showing that GGT is prognostically useful even for small size tumors and in HCC patients who do not have elevated serum AFP levels and in a description of their associated tumor characteristics. The addition of serum albumin to GGT values slightly enhanced its usefulness. However, GGT also has limitations for discriminating amongst small tumors.

\section{Disclosure statement}

The authors declare no conflict of interest. All authors have read and agree with this paper.

\section{Funding}

This work is supported in part by NIH grant CA 82723 (B.I.C).

\section{Author contributions and acknowledgements}

BIC and HA- concept and ideas. BIC-writing; HGB-statistics; UK, $\mathrm{KY}, \mathrm{NE}, \mathrm{AO}, \mathrm{EA}, \mathrm{HY}, \mathrm{HS}, \mathrm{AU}, \mathrm{AB}, \mathrm{SK}, \mathrm{OU}, \mathrm{YU}, \mathrm{BG}$ and $\mathrm{AD}$ - data collection, database formation and quality of data evaluation from original source documents.

\section{Statement of ethics}

This work complies with the guidelines of the World Medical Association, Declaration of Helsinki. This work was approved by each institution's IRB as documented in the methods section.

\section{References}

1. Okuda K, Ohtsuki T, Obata H, Tomimatsu M, Okazaki N, et al. (1985) Natural history of hepatocellular carcinoma and prognosis in relation to treatment. Study of 850 patients. Cancer 56: 918-928. [Crossref]

2. Peng Y, Wei Q, He Y, Xie Q, Liang Y, et al. (2020) ALBI versus child-pugh in predicting outcome of patients with HCC: A systematic review. Expert Rev Gastroenterol Hepatol 14: 383-400. [Crossref]

3. Llovet JM, Fuster J, Bruix J (2004) Barcelona-Clínic liver cancer group. The Barcelona approach: diagnosis, staging, and treatment of hepatocellular carcinoma. Liver Transpl 10: S115-S120. 
4. Omata M, Cheng AL, Kokudo N, Kudo M, Lee JM, et al. (2017) Asia-Pacific clinical practice guidelines on the management of hepatocellular carcinoma: a 2017 update. Hepatol Int 11: 317-370. [Crossref]

5. Liebman HA, Furie BC, Tong MJ, Blanchard RA, Lo KJ, et al. (1984) Des-gammacarboxy (abnormal) prothrombin as a serum marker of primary hepatocellular carcinoma. $N$ Engl J Med 310: 1427-1431.

6. Koike Y, Shiratori Y, Sato S, Obi S, Teratani T, et al. (2001) Des-gamma-carboxy prothrombin as a useful predisposing factor for the development of portal venous invasion in patients with hepatocellular carcinoma: a prospective analysis of 227 patients. Cancer 91: 561-569. [Crossref]

7. Carr BI, Buch SC, Kondragunta K, Pancoska P, Branch RA, et al. (2008) Tumor and liver determinants of prognosis in unresectable hepatocellular carcinoma: A case cohort study. J Gastroenterol Hepatol 23: 1259-1266.

8. Utsunomiya T, Ishikawa D, Asanoma M, Yamada S, Iwahashi S, et al. (2014) Specific miRNA expression profiles of non-tumor liver tissue predict a risk for recurrence of hepatocellular carcinoma. Hepatol Res 44: 631-638. [Crossref]

9. Hashimoto K, Ikeda Y, Korenaga D, Tanoue K, Hamatake M, et al. (2005) The impact of preoperative serum C-reactive protein on the prognosis of patients with hepatocellular carcinoma. Cancer 103: 1856-1564.

10. Horino K, Beppu T, Kuroki H (2013) Glasgow Prognostic Score as a useful prognostic factor after hepatectomy for hepatocellular carcinoma. Int J Clin Oncol 18: 829-838. [Crossref]

11. Bağırsakçı E, Șahin E, Atabey N, Erdal E, Guerra V, et al. (2017) Role of Albumin in Growth Inhibition in Hepatocellular Carcinoma. Oncology 93: 136-142.

12. Carr BI, Kanke F, Wise M, Satomura S (2007) Clinical evaluation of lens culinaris agglutinin-reactive alpha-fetoprotein and des-gamma-carboxy prothrombin in histologically proven hepatocellular carcinoma in the United States. Dig Dis Sci 52: 776-782.

13. Lorente L (2018) New prognostic biomarkers of mortality in patients undergoing liver transplantation for hepatocellular carcinoma. World J Gastroenterol 24: 4230-4242. [Crossref]

14. Toyoda H, Kumada T, Osaki Y, Oka H, Urano F, et al. (2006) Staging hepatocellular carcinoma by a novel scoring system (BALAD score) based on serum markers. Clin Gastroenterol Hepatol 4: 1528-1536.

15. Hanigan MH, Pitot HC (1985) Gamma-glutamyl transpeptidase--its role in hepatocarcinogenesis. Carcinogenesis 6: 165-172.

16. Corti A, Franzini M, Paolicci A, Pompella A (2010) Gamma-glutamyltransferase of cancer cells at the crossroads of tumor progression, drug resistance and drug targeting. Anticancer Res 30: 1169-1182.

17. Hanigan MH (2014) Gamma-Glutamyl Transpeptidase: Redox Regulation and Drug Resistance. Adv Cancer Res 122: 103-141. [Crossref]

18. Carr BI, Pancoska P, Branch RA (2010) Significance of increased serum GGTP levels in HCC patients. Hepatogastroenterology 57: 869-874.

19. Zhang JB, Chen Y, Zhang B, Xie X, Zhang L, et al. (2011) Prognostic significance of serum gamma- glutamyl transferase in patients with intermediate hepatocellular carcinoma treated with transcatheter arterial chemoembolization. Eur J Gastroenterol Hepatol 23: 787-793.

20. Fu S, Guo Z, Li S, Kuang M, Hu W, et al. (2016) Prognostic value of preoperative serum $\gamma$ - glutamyltranspeptidase in patients with hepatocellular carcinoma after hepatectomy. Tumour Biol 37: 3433- 3440.

21. Ma H, Zhang L, Tang B, Wang Y, Chen R, et al. (2014) Glutamyltranspeptidase is a prognostic marker of survival and recurrence in radiofrequency-ablation treatment of hepatocellular carcinoma. Ann Surg Oncol 21: 3084- 3089. [Crossref]

22. Akkiz, H, Carr BI, Yalcin KK, Guerra V, Kuran S, et al. (2018) Characteristics of Hepatocellular Carcinoma Aggressiveness Factors in Turkish Patients. Oncology 94: 116-124

23. Carr BI, Guerra V, Giannini EG, Farinati F, Ciccarese F, et al. (2014) Low alphafetoprotein HCC and the role of GGTP. Int J Biol Markers 29: e395-e402.

24. Yang JG, He XF, Huang B (2018) Rule of changes in serum GGT levels and GGT/ALT and AST/ALT ratios in primary hepatic carcinoma with different AFP levels. Cancer Biomark 21: 743-746.

25. Giannini EG, Marenco S, Borgonovo G, Savarino V (2012) Italian liver cancer (ITA. LI.CA) group. Alpha-fetoprotein has no prognostic role in small hepatocellular carcinoma identified during surveillance in compensated cirrhosis. Hepatol 56: 13711379. [Crossref]
26. Zhang C-H, Ni X-C, Chen B-Y, Qiu S-J, Zhu Y-M, et al. (2019) Combined preoperative albumin-bilirubin (ALBI) and serum $\gamma$-glutamyl transpeptidase (GGT) predicts the outcome of hepatocellular carcinoma patients following hepatic resection. $J$ Cancer 10: 4836-4845.

27. Wang L, Li Q, Zhang J, Lu J (2019) A novel prognostic scoring model based on albumin and $\gamma$-glutamyltransferase for hepatocellular carcinoma prognosis. Cancer Manag Res 11: $10685-10694$

28. Zhang LX, Lv Y, Xu AM, Wang HZ (2019) The prognostic significance of serum gamma-glutamyltransferase levels and AST/ALT in primary hepatic carcinoma. BMC Cancer 19: 841 .

29. Zhu J, Jiang F, Ni HB, Xiao MB, Chen BY, et al. (2013) Combined analysis of serum $\gamma$-glutamyl transferase isoenzyme II, $\alpha$-L-fucosidase and $\alpha$-fetoprotein detected using a commercial kit in the diagnosis of hepatocellular carcinoma. Exp Ther Med 5: 89-94. [Crossref]

30. Shi S, Chen Q, Ye L, Yin D, Li X, et al. (2017) Prognostic value of systemic inflammation score in patients with hepatocellular carcinoma after hepatectomy. Oncotarget 8: 79366-79375.

31. Pang Q, Bi JB, Wang ZX, Xu XS, Qu K, et al. (2016) Simple models based on gammaglutamyl transpeptidase and platelets for predicting survival in hepatitis B-associated hepatocellular carcinoma. Onco Targets Ther 9: 2099-2109. [Crossref]

32. Sun P, Li Y, Chang L, Tian X (2019) Prognostic and clinicopathological significance of Gamma-Glutamyltransferase in patients with hepatocellular carcinoma. Medicine (Baltimore) 98: e15603.

33. Whitfield JB (2001) Gamma glutamyl transferase. Crit Rev Clin Lab Sci 38: 263-355.

34. Everhart JE, Wright EC (2013) Association of $\gamma$-glutamyl transferase (GGT) activity with treatment and clinical outcomes in chronic hepatitis C (HCV). Hepatology 57: 1725-1733. [Crossref]

35. Corti A, Duarte TL, Giommarelli C, De Tata V, Paolicchi A, et al. (2009) Membrane gamma-glutamyl transferase activity promotes iron-dependent oxidative DNA damage in melanoma cells. Mutat Res 669: 112-121.

36. Stark AA, Russell JJ, Langenbach R, Pagano DA, Zeiger E, et al. (1994) Localization of oxidative damage by a glutathione-gamma-glutamyl transpeptidase system in preneoplastic lesions in sections of livers from carcinogen- treated rats. Carcinogenesis 15: 343-348.

37. Borud O, Mortensen B, Mikkelsen IM, Leroy P, Wellman M, et al. (2000) Regulation of gamma-glutamyltransferase in cisplatin-resistant and -sensitive colon carcinoma cells after acute cisplatin and oxidative stress exposures. Int J Cancer 88: 464-468.

38. Xia J, Song P, Sun Z, Sawakami T, Jia M, et al. (2016) Advances of diagnostic and mechanistic studies of $\gamma$-glutamyl transpeptidase in hepatocellular carcinoma. Drug Discov Ther 10: 181-187. [Crossref]

39. Bansal A, Sanchez DJ, Nimgaonkar V, Sanchez D (2019) Gamma-Glutamyltransferase 1 Promotes Clear Cell Renal Cell Carcinoma Initiation and Progression. Mol Cancer Res 17: 1881-1892.

40. Priolo C, Khabibullin D, Reznik E, Filippakis H, Ogórek B, et al. (2018) Impairment of gamma-glutamyl transferase 1 activity in the metabolic pathogenesis of chromophobe renal cell carcinoma. Proc Natl Acad Sci U S A 115: E6274-E6282. [Crossref]

41. Lieberman MW, Wiseman AL, Shi ZZ, Carter BZ, Barrios R, et al. (1996) Growth retardation and cysteine deficiency in gamma-glutamyl transpeptidase-deficient mice. Proc Natl Acad Sci U S A 93: 7923-7926. [Crossref]

42. Hanigan M (1995) Expression of gamma-glutamyl transpeptidase provides tumor cells with a selective growth advantage at physiologic concentrations of cyst(e)ine. Carcinogenesis 16: 181-185.

43. Sulakhe SJ, Lautt WWS (1987) Characterization of gamma-glutamyl transpeptidase in normal, perinatal, premalignant and malignant rat liver. Int J Biochem 19: 23-32. [Crossref]

44. Vanderlaan M, Phares W (1891) gamma-Glutamyltranspeptidase: a tumor cell marker with a biological function. Histochem $J$ 13: 865-877.

45. Sacchetti L, Castaldo G, Salvatore F (1988) The gamma-glutamyltransferase isoenzyme pattern in serum as a signal discriminating between hepatobiliary diseases, including neoplasias. Clin Chem 34. [Crossref]

46. Xu K, Meng XY, Wu JW, Shen B, Shi YC, et al. (1992) Diagnostic value of serum gamma-glutamyl transferase isoenzyme for hepatocellular carcinoma: a 10-year study. Am J Gastroenterol 87: 991-995. 
47. Zhu J, Jiang F, Ni HB, Xiao MB, Chen BY, et al. (2013) Combined analysis of serum $\gamma$-glutamyl transferase isoenzyme II, $\alpha$-L-fucosidase and $\alpha$-fetoprotein detected using a commercial kit in the diagnosis of hepatocellular carcinoma. Exp Ther Med 5: 89-94. [Crossref]
48. Tsutsumi M, Sakamuro D, Takada A, Zang SC, Furukawa T, et al. (1996) Detection of a unique gamma-glutamyl transpeptidase messenger RNA species closely related to the development of hepatocellular carcinoma in humans: a new candidate for early diagnosis of hepatocellular carcinoma. Hepatology 23: 1093-1097. [Crossref]

Copyright: (C2020 Carr BI. This is an open-access article distributed under the terms of the Creative Commons Attribution License, which permits unrestricted use, distribution, and reproduction in any medium, provided the original author and source are credited. 